\title{
Atrioventricular conduction system in univentricular heart of right ventricular type with right-sided rudimentary chamber
}

\author{
CATHARINA E ESSED, SIEW YEN HO, STEWART HUNTER, AND \\ ROBERT H ANDERSON
}

From the Departments of Paediatrics and Surgery, Cardiothoracic Institute, Brompton Hospital, London, and Freeman Road Hospital, Newcastle upon Tyne

ABSTRACT The conduction tissue in a univentricular heart of the right ventricular type with a right-sided rudimentary chamber was studied. Both an anterior and conventional node were found, the anterior node being positioned in the atrial septum very close to the conventional node. Between the two nodes, a sling of conduction tissue passed through the annulus fibrosus but was not related to the trabecular septum. A non-branching bundle descended on to a free-running trabecula in the main ventricular chamber, the trabecular septum itself being devoid of conduction tissue. We believe it is likely that this trabecula represents the trabecula septomarginalis of the normal right ventricle. It has recently been suggested that during development the primordium of the trabecula septomarginalis is the structure which carries the conduction tissue from the atrioventricular node (whatever its position) to the trabecular septum. The present findings seem to support this.

It is now well established that the atrioventricular conduction tissue in univentricular hearts of left ventricular type penetrates from an anterior node, while the course of the non-branching bundle is dependent on the position of the rudimentary chamber..$^{1-3}$ It is also known that in univentricular hearts of right ventricular type the penetrating bundle takes origin from the conventional (posterior) node, and the non-branching bundle descends on the trabecular septum, which in these hearts extends to the crux cordis. ${ }^{4}$ However, thus far univentricular hearts of right ventricular type have been studied only when the rudimentary chamber of left ventricular type was left-sided. The question remains concerning the conduction tissue disposition in these hearts when the rudimentary chamber is right-sided. This is because such hearts are closely related to cases of congenitally corrected transposition, and in the latter anomaly an anterior node and conduction system are found, despite the fact that the septum extends to the crux. ${ }^{5}$

Address for reprint requests: Dr RH Anderson, Department of Paediatrics, Cardiothoracic Institute, Brompton Hospital, Fulham Road, London SW3 6HP.
This doubt is endorsed by cases recently examined with congenitally corrected transposition and straddling of the right atrioventricular valve, hearts which show features intermediate between those of classically corrected transposition and univentricular hearts of right ventricular type with right-sided rudimentary chamber. ${ }^{6}$ In the hearts studied with straddling valves, two had anterior conduction tissues alone while another had both regular and anterior nodes with a ventricular "sling" of conduction tissue. ${ }^{6}$

In view of the uncertainty produced by these considerations, we have studied an example of univentricular heart of right ventricular type with right-sided rudimentary chamber, to try to establish the precise disposition of the atrioventricular conduction tissues.

\section{Case report}

The patient was a male child born of healthy unrelated parents after a full-term normal pregnancy. The delivery was uncomplicated. There had been no contact with infectious diseases or drugs during the pregnancy. The infant was admitted to hospital 
on the sixth day of life because of cyanosis. Chest radiography showed a normal sized heart with pulmonary oligaemia, and the electrocardiogram was interpreted as showing right ventricular hypertrophy with some right atrial enlargement. The $T$ waves were noted to be flattened in all leads. Although the patient was not in heart failure, he exhibited continuing cyanosis despite oxygen therapy and became increasingly dyspnoeic. He therefore underwent cardiac catheterisation on the day of admission. The catheter was advanced from the right saphenous vein to the right atrium, then passed to a ventricular chamber and thence to the aorta. The catheter could also be passed through an atrial septal defect, across a different atrioventricular valve, and into the same ventricular chamber and the aorta. The pulmonary artery was never entered, and it was not possible to detect a second ventricular chamber. Angiograms confirmed a double inlet to a coarsely trabeculated ventricular chamber of right ventricular morphology and indicated the presence of pulmonary atresia, with small pulmonary arteries filling through a ductus arteriosus. An aortopulmonary anastomosis was considered as a necessary operation, but the infant suffered cardiac arrest and died before this could be performed.

At necropsy it was shown that there was situs solitus of the atria. Both aortic arch and apex were to the left. The right atrium was distended but received normal systemic venous drainage. The foramen ovale was patent. The pulmonary veins drained normally into the left atrium. Both right and left atrioventricular orifices communicated in their entirety with the same ventricular chamber. This chamber had a trabecular pattern of right ventricular type (fig 1a). Within the right and posterior wall of this main chamber 웅 a small rudimentary chamber with left ventricula年 pattern was found. The septum separating the chambers extended to the crux and was delimite 8 externally by the anterior and posterior descending coronary arteries (fig 1 b). The rudimentary cham $\vec{\circ}$ ber communicated with the ventricle through $\dot{a}$ small septal defect, but had no direct inlet of outlet. There was a single outlet from the main ventricle, this artery being an aorta. Its orifice was positioned in front of the two atrioventriculaor orifices and the aortic valve was supported by complete muscular infundibulum (fig 1a). Ther $\vec{e}$ was atresia of the pulmonary outflow tract and trunk, the remnant of the trunk being positioned to the right and slightly behind the aorta. The pulmonary arteries arose from a confluence fef through a narrow ductus arteriosus.

Within the main chamber a prominent muscula trabecula separated the atrioventricular valves $\overrightarrow{c 0}$ giving tension apparatus to each valve, and ex®o tended upwards to the underside of the atrial septum (figs 1a, 2a). On gross examination white "streaks" reminiscent of the conduction tissues were seen on the left aspect of the trabecula.

The diagnosis was: (1) solitus-double inle ventricle-single outlet heart, (2) univentricula? heart of right ventricular type with right-side $\overrightarrow{\widehat{B}}$ trabecular pouch, and (3) pulmonary atresia.

A block of tissue was removed which contained the trabecular pouch, the right atrioventricular orifice, the trabecular septum, the prominent main chamber trabecula cut at its attachment to the the trabecular pouch, the right atrioventricular cular orifice, and the lower part of the atriag septum (fig 2a, b).

It was sectioned perpendicular to the trabeculap

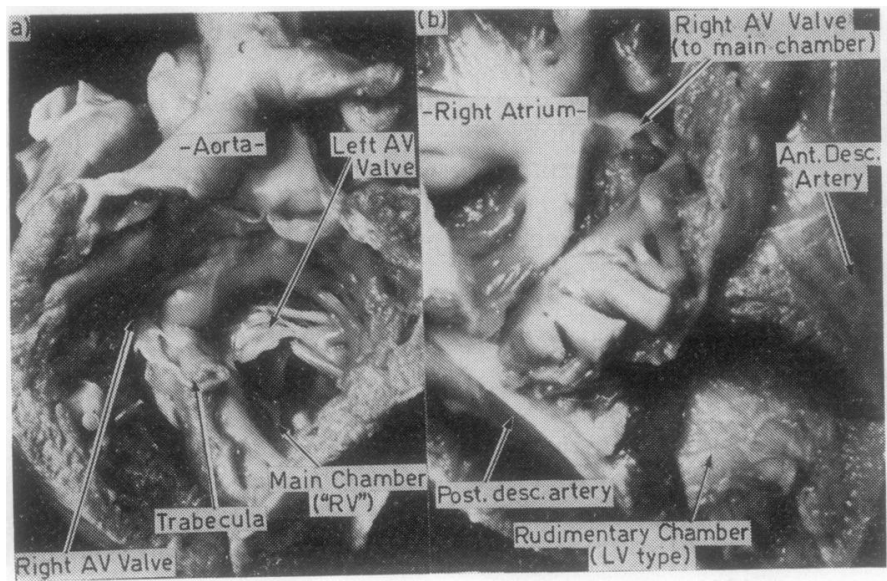

Fig 1 (a) The main chamber with trabecular pattern of right ventricular type and the position of the trabecula in relation to the right and left atrioventricular orifices and the aorta. (b) The rudimentary chamber of left ventricular type. Note that the trabecular? septum extends to the crux cordis, indicated by the posterior descending coronary artery and the atrial septum. 
septum, using the technique of Smith et al. ${ }^{7}$ The sections were 10 microns thick, and every twentyfifth section was mounted and stained with a trichrome technique.

\section{Results}

A conventional node was found in its expected position at the apex of the triangle of Koch (fig 3a). It formed a penetrating bundle which reached the crest of the free-running main chamber trabecula (fig 3b). However, immediately the bundle ascended again through the fibrous annules to become an anterior nodelike structure (fig 3c). A sling was therefore produced in the base of the annulus fibrosus on the top of the trabecular attachment. The anterior nodelike structure was positioned very close to the posterior

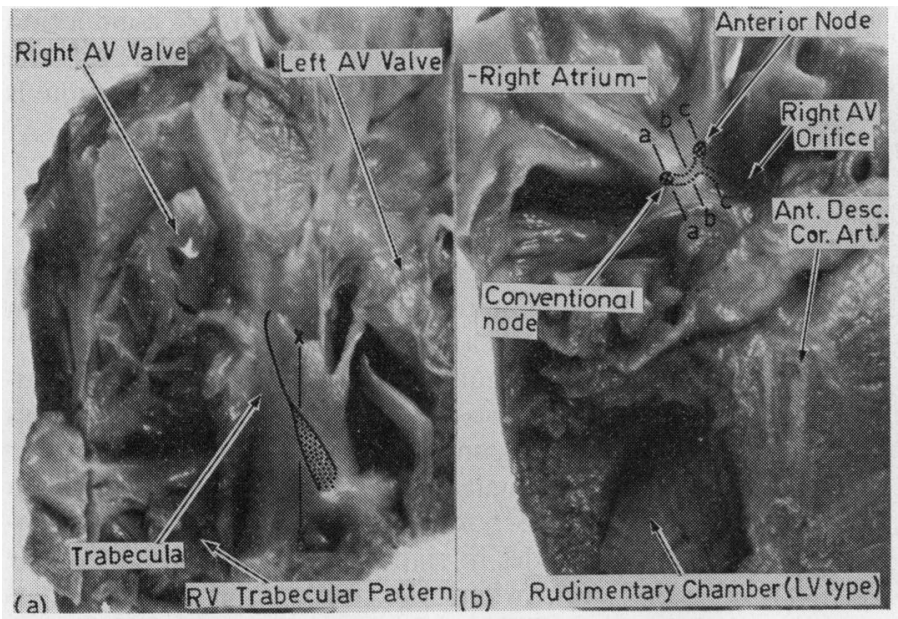

Fig 2 (a) The main chamber view of the block of tissue removed for study of the conduction tissue. Note the "streaks" on the trabecula. A section has been taken through the area marked " $x-x$," and corresponds with fig 4. (b) The rudimentary chamber view of the same block of tissue. The position of the conventional and anterior nodes with the conduction tissue sling are marked. The sections taken through the areas marked " $a-a$, ," " $b-b$," "c-c," correspond respectively with figs $3 a, b$, and $c$.

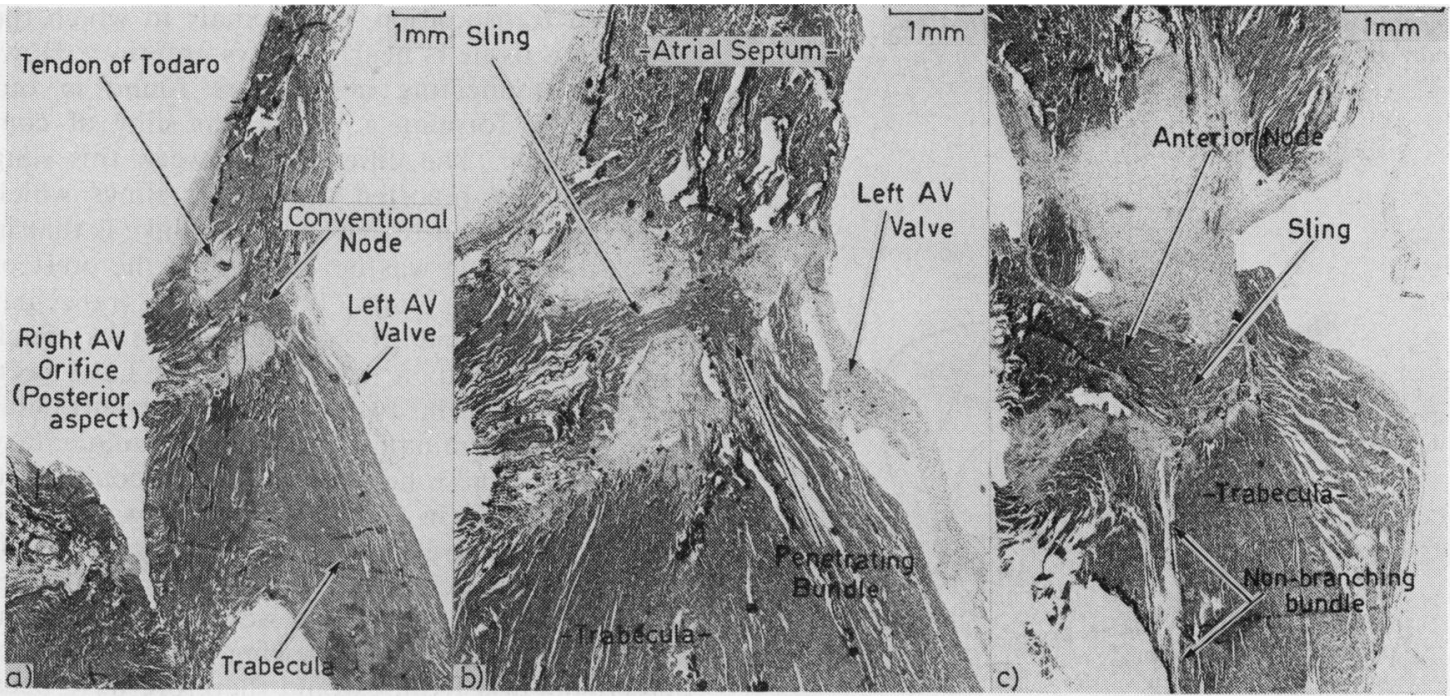

Fig 3 (a) The posterior node with normal relationship to the tendon of Todaro. (This section corresponds with the mark " $a-a$ " in fig 2b). (b) The penetrating bundle from the conventional node in the annulus fibrosus. The anterior part of the sling is seen passing through the annulus towards the anterior node, corresponding with the mark " $b-b$ " in fig $2 b$. (c) The anterior node at its junction with the sling. Beneath the sling is seen the slender non-branching bundle extending downwards towards the trabecula, corresponding with the mark " $c-c$ " in fig $2 b$. 


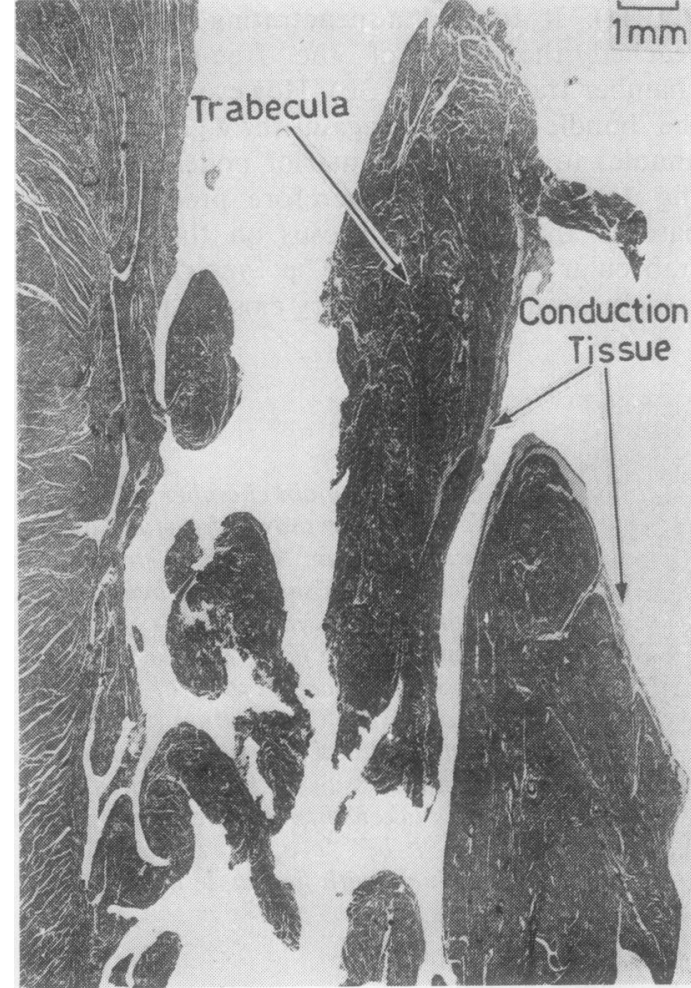

Fig 4 The conduction tissue on the left side of the trabecula. This conduction tissue corresponded to the white "streaks" seen on gross examination, corresponding with the mark " $x-x$ " in fig $2 a$.

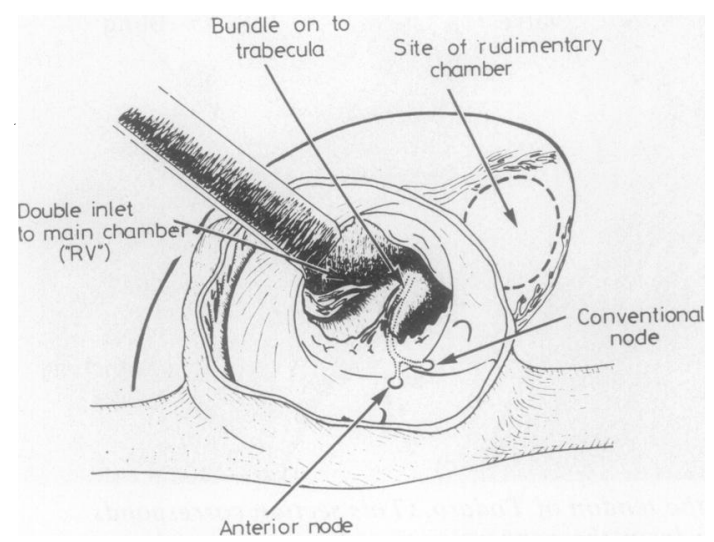

Fig 5 Artist's impression of the disposition of the conduction tissue in the heart studied as it would have appeared to the surgeon looking through the right atrium. node within the atrial septum (fig $2 b$ ). From th sling a slender bundle was found to descend along the right and anterior side of the trabecula, wit out branching. Along the left margin of the trabecula below the attachment of a chorda the left atrioventricular valve, further bundlelike structures were seen (fig 4). These, however, had no contact with the remaining conduction tissues The left-sided structures corresponded to the "streaks" observed on gross examination (fig $2 a$ )

No conduction tissue was found in the trabecular septum. The overall distribution of conduction tissue as it might have been viewed by the surgeon approaching through the right atrium is shown in fig 5.

\section{Discussion}

Previous investigations have shown that whiege anterior conduction systems are the rule univentricular hearts of the left ventricular type, the atrioventricular conduction system in unt ventricular hearts of right ventricular type take origin from a conventionally situated node. ${ }^{4}$ Oy present investigation shows that the conduction system is still posterior, originating from a comventional node, in right ventricular univentriculogir hearts even when the rudimentary chamber ofs right-sided. This is of interest because such hearts can be considered "close cousins" to congenitalథ corrected transposition, an anomaly in which the conduction tissue is nearly always anterior. ${ }^{5}$ How ever two connecting nodes were found in our present case forming a ventricular sling of duction tissue. The difference between this sliag and previously reported ventricular slings whief have recently been reviewed by Wenink ${ }^{8}$ is that our case the sling was not related to the crest of the trabecular septum. Indeed, the trabecular septum was devoid of conduction tissues. Suef slings unrelated to a septal structure have beeh observed before in two cases of univentricular heart of indeterminate type without rudimenta䄱 chamber. ${ }^{9}$ In these hearts the sling of conduction tissue was found in the posterolateral wall of the ventricle. The surgical significance of our case is that the bundle descended down a prominent free running trabecula. The heart would have been impossible to septate without sewing to this structure The conduction tissues would therefore have been at considerable risk should surgical repair hate been attempted.

Conduction tissue has previously been found free-running trabeculae in univentricular hearts of indeterminate type $\mathrm{p}^{1011}$ and in one of the cases 
univentricular hearts of right ventricular type with left-sided rudimentary chamber. ${ }^{4}$ What is the nature of the trabecula? It is tempting to speculate that it is the trabecula septomarginalis. Wenink ${ }^{3}$ has commented on the significance of the trabecula septomarginalis in forming the anterior septum in univentricular hearts of left ventricular type and has since developed this concept to suggest that the trabecula septomarginalis is the structure which carries the ventricular conduction tissues from the atrioventricular node, whatever its position, to the trabecular septum (Wenink, personal communication, 1979). We have previously argued that the ventricular conduction tissue is carried on the trabecular septum, and that it is the orientation of this septum which determines the position of the connecting atrioventricular node. ${ }^{12}$ The present case, which has divorce of the trabecula septomarginalis from the trabecular septum, the latter structure being devoid of conduction tissue despite extending to the crux, suggests that our initial concept was simplistic. Instead it lends strong support to the alternative concept advanced by Wenink.

The findings in the present and other cases ${ }^{41011}$ suggest that the surgeon should suspect that a freerunning prominent trabecula may carry conduction tissue in a univentricular heart whenever it extends to make contact with the atrioventricular junction. In this circumstance the trabecular septum may be a poor guide to the penetrating bundle even though the septum extends to the crux cordis.

We are grateful to Dr D Scott of Newcastle General Hospital who performed the initial postmortem examination of this case and gave us permission to carry out the further investigations. We are also indebted to Miss Noelle de Freitas for help in the preparation of the manuscript. CEE was a visiting fellow from the Department of Thoracic Surgery, Thoraxcenter, Academic Hospital "Dijkzigt", Rotterdam, the Netherlands. RHA is supported by the Joseph Levy Foundation and the British Heart Foundation.

\section{References}

1 Anderson RH, Arnold R, Thapar MK, Jones RS, Hamilton DI. Cardiac specialized tissue in hearts with an apparently single ventricular chamber. (Double inlet left ventricle.) $\mathrm{Am} \mathrm{J}$ Cardiol 1974; 33:95-106.

2 Bharati S, Lev M. The course of the conduction system in single ventricle with inverted (L) loop and inverted (L) transposition. Circulation 1975; 51:723-30.

3 Wenink ACG. The conducting tissues in primitive ventricle with outlet chamber: two different possibilities. J Thorac Cardiovasc Surg 1978; 75:74753.

4 Wilkinson JL, Dickinson DF, Smith A, Anderson RH. Univentricular heart of right ventricular type with double or common inlet. J Thorac Cardiovasc Surg 1980; in press.

5 Anderson RH, Becker AE, Arnold R, Wilkinson $\mathrm{JL}$. The conducting tissues in congenitally corrected transposition. Circulation 1974; 50:911-24.

6 Becker AE, Ho SY, Caruso G, Anderson RH. Straddling mitral valve in congenitally corrected transposition of the great arteries. Circulation 1980 ; in press.

7 Smith A, Ho SY, Anderson RH. Histological study of the cardiac conducting system as a routine procedure. Med Lab Sci 1977; 34:223-9.

8 Wenink ACG. Congenitally complete heart block with an interrupted Mönckeberg sling. Eur J Cardiol 1979; 9:89-99.

9 Dickinson DF, Wilkinson JL, Anderson KR, Smith A, Ho SY, Anderson RH. The cardiac conducting tissues in situs ambiguus. Circulation 1980 ; in press.

10 Wilkinson JL, Anderson RH, Arnold R, Hamilton DI, Smith A. The conducting tissues in primitive ventricular hearts without an outlet chamber. Circulation 1976; 53:930-8.

11 Wilkinson JL, Becker AE, Anderson RH. Morphology and conduction tissue in primitive ventricle with two atrioventricular valves. In: Anderson RH, Shinebourne, EA, eds. Paediatric Cardiology 1977. Edinburgh: Churchill Livingstone, 1978; 323-38.

12 Anderson RH, Wilkinson JL, Becker AE. Conducting tissues in the univentricular heart. In Van Mierop LHS, Oppenheimer-Dekker A, eds. Embryology and Teratology of the Heart and Great Arteries. The Hague: Martinus Nijhoff, 1978; 62-78. 